\title{
FEIRA DE CIÊNCIAS COMO ESPAÇO DE FORMAÇÃO E DESENVOLVIMENTO DE PROFESSORES E ALUNOS
}

\author{
Science fairs as space of formation and development of teachers and pupils
}

\author{
Luciana de Nazaré Farias ${ }^{1}$ \\ Terezinha Valim Oliver Gonçalves ${ }^{2}$
}

\section{RESUMO}

Nesta pesquisa narrativa buscamos analisar em que medida as Feiras de Ciências podem configurar-se como espaços de formação e desenvolvimento de professores e alunos. Para tanto, analisamos entrevistas semi-estruturadas que desenvolvemos com seis professores e cinco alunos, participantes da XI FEICIPA - Feira de Ciências do Estado do Pará que ocorreu no município de Abaetetuba PA, em dezembro de 2003. Constituíram-se, também, objeto de análise os diários de pesquisa e documentos referentes à realização das Feiras de Ciências no Estado do Pará. Percebemos, a partir do relato dos sujeitos de pesquisa, diferentes oportunidades formativas advindas das experiências por eles vividas/compartilhadas em Feiras de Ciências. São valorizadas pelos sujeitos investigados as oportunidades de socialização e troca de experiências no âmbito da trilogia ensino-aprendizagem-conhecimentos, possibilitando uma ampliação da visão de mundo dos participantes e expositores da Feira, permitindo a divulgação dos resultados das pesquisas realizadas, troca de experiências entre os pares, como forma de validação dos conhecimentos construídos a partir da realidade investigada.

Palavras-chave: Feira de Ciências; pesquisa narrativa; formação e desenvolvimento profissional.

\footnotetext{
ABSTRACT

In this narrative research we analyzed in which sense the Science Fairs can set themselves up as spaces for theachers and students' education and development. Therefore, we analyzed semistructured interviews we made with six
}

teachers and five students, participants of the XI FEICIPA - XI Science Fair of Pará State - that occurred in the city of Abaetetuba - PA in December, 2003. It was also constituted as object of analysis the diaries research and documents concerning the conduct of Science Fairs in the State of Pará noticed from the report of the study subjects, different education opportunitiest resulingt from the experiences they lived / shared in Science Fairs by the subjects investigated value the opportunities to socialize and exchange experiences in the trilogy teaching-learning-knowledge, enabling a worldview expansion of the participants and exhibitors at the fair, allowing the dissemination of researches' results, experiences exchange between pairs as a way of validating knowledge built from the reality investigated.

Keywords: Science Fair; Narrative research; Education and professional development.

\section{INTRODUÇÃO}

Nesta pesquisa narrativa (CONNELLY E CLANDININ, 1995), buscamos analisar em que termos as Feiras de Ciências podem configurarse como espaços de formação e desenvolvimento de professores e alunos. Para tanto, analisamos entrevistas semi-estruturadas que desenvolvemos com professores e alunos, participantes da XI FEICIPA ${ }^{3}$.

Defendemos a ideia de que as Feiras de Ciências podem constituir-se espaços diferenciados de ensino-aprendizagem em relação a uma abordagem tradicional, no que diz respeito às relações constitutivas entre professor - alunos - conhecimento. Conforme consideram Gonçalves (2000), Mancuso (2000), Henning

\footnotetext{
${ }^{1}$ Professora de Ciências e Biologia. Mestre em Educação em Ciências e Matemáticas NPADC/UFPa PA/Brasil.

${ }^{2}$ Professora Formadora de Professores de Ciências e Biologia. Doutora em Educação UNICAMP/SP Brasil. Coordenadora do Programa de Pós-graduação em Educação em Ciências e Matemáticas NPADC/UFPA.

${ }^{3}$ Feira de Ciências do Estado do Pará - que ocorreu no município de Abaetetuba PA, em dezembro de 2003.
} 
(1986), Pereira et al (2000) e Oaigen (2004).

Em segundo lugar, as Feiras de Ciências caracterizam-se como eventos que são realizados em escolas ou na comunidade, com a intenção de, durante a exposição dos trabalhos, oportunizar um diálogo com os visitantes e a discussão acerca dos conhecimentos, das metodologias de pesquisa e da criatividade dos alunos envolvidos (MANCUSO, 2000). Henning (1986) considera que as Feiras de Ciências se constituem uma atividade em que o aluno realiza trabalhos de investigação científica e, posteriormente, faz a demonstração dos resultados obtidos.

Para Pereira et al (2000), as Feiras de Ciências são atividades de cunho técnico, cultural e científico que se destinam a estabelecer a união científico-cultural entre os estudantes do ensino básico (fundamental e médio), regularmente matriculados em Unidades de Ensino Particular e Público, inclusive acadêmicos de Iniciação Científica. Nesse sentido, as Feiras de Ciências, constituem-se momentos importantes no que tange à possibilidade de disseminação da produção científica dos envolvidos, caracterizando uma oportuna troca de experiências e conhecimentos, além de despertar para a continuidade dos trabalhos e o aprofundamento teórico-prático dos mesmos (OAIGEN, 2004).

Para Pavão (2006), as Feiras de Ciências podem ser utilizadas para repetição de experiências realizadas em sala de aula; montagem de exposições com fins demonstrativos; como estímulo para aprofundar estudos e busca de novos conhecimentos; oportunidade de proximidade com a comunidade científica; espaço para iniciação científica; desenvolvimento do espírito criativo; discussão de problemas sociais e integração escola-sociedade. Mas, acima de tudo, a feira deve estar integrada ao currículo, sendo preparada desde o início do período letivo para que o momento da apresentação seja o coroamento de todo um trabalho.

Uma característica que consideramos essencial em relação a um ensino como/por pesquisa é que a elaboração dos projetos de investigação constitui-se num processo contínuo de interação entre professor e alunos, voltado para o desenvolvimento pessoal dos envolvidos.

Entendemos que as Feiras de Ciências no Pará configuram-se também como oportunidades formativas para os professores, à medida que oferecem oportunidades de discussão das práticas pedagógicas dos professores, seja por apresentação propriamente dita de experiências refletidas/estudadas seja pela discussão mais informal nas atividades paralelas e nos momentos de avaliação (GONÇALVES, 2000).

Reconhecer que as aulas de ciências podem ser desenvolvidas por meio do exercício da pesquisa, por professores e alunos, implica considerar que ambos podem construir ideias, interpretações e conhecimentos acerca dos fatos e fenômenos da vida. Nessa perspectiva, as aulas são um contexto natural de investigação, pois " $o$ que ocorre em seu interior adquire um sentido próprio profundo para professores, alunos e a sociedade"(CORZO et al, 2004, p.2).

Segundo Bagno (2003), Stenhouse (1985), Moraes, Galiazzi e Ramos (2002), pesquisa é um processo em que professores e alunos se envolvem mutuamente com o intuito de durante esse processo de busca de informações novas, construir juntos um conhecimento que lhes é próprio, peculiar. Deste modo, buscamos analisar em que medida as Feiras de Ciências podem configurar-se como espaços de formação e desenvolvimento de professores e alunos.

\section{METODOLOGIA}

Utilizamos a investigação narrativa pelo fato de trabalharmos com experiências profissionais que constituem as histórias de vida de professores (NÓVOA, 1992) e alunos. É crescente no Brasil o número de pesquisas qualitativas na modalidade narrativa principalmente na área da educação. Como podemos observar nos trabalhos de Chaves (2000), Gonçalves (2000, 2004), Aragão (2004), dentre outros.

$\mathrm{Na}$ presente pesquisa, utilizamos como recursos metodológicos: diário de campo, documentos e sites do NPADC e realizamos a gravação em áudio e posterior transcrição de entrevistas semi-estruturadas que desenvolvemos com professores e alunos participantes da XI Feira de Ciências do Estado 
do Pará FEICIPA, ocorrida em dezembro de 2003, no município de Abaetetuba, Pará.

Realizamos a interpretação das falas por meio da análise de conteúdo (Franco, 2003). Na sistematização das análises, adotamos o que Gonçalves (2000) denominou "Categorias interativas", possibilitando "idas e vindas" aos relatos dos sujeitos, sem a pretensão de "cerceálos" ou de colocá-los em categorias fechadas. Neste artigo, estão presentes 6 professores e 5 alunos participantes da XI FEICIPA.

\section{A N Á L I E D E R E S ULTA D O S : SIGNIFICADOS FORMATIVOS}

Consideramos que a experiência dos sujeitos como professores-orientadores na elaboração de projetos de pesquisa e sua socialização em Feiras de Ciências possibilitou, de certa forma, que eles refletissem sobre a formação incidental (idem) que vivenciaram como alunos na produção de trabalhos escolares. Esse aspecto pôde ser evidenciado nas falas dos sujeitos que entrevistamos:

[...] mas o que ficou na minha cabeça foi que o professor mostrou um livro com um experimento de física e disse que nos tínhamos que reproduzir igualzinho do livro, por que ia cair na prova, então a gente tinha que estudar. $\mathrm{Eu}$ achei positivo. Porque eu lembro que a gente tinha que estudar pra prova tinha que dar um trabalho feito pra feira. O grupo era bom, a gente tinha um grupo de estudos, a gente aproveitou o grupo para trabalhar nisso, a gente discutiu muito, alguns tinham uma facilidade de lidar com a física, a gente acabou explicando na feira aquilo que a gente aprendeu no livro, mas a gente explicava exclusivamente o que estava no livro, tudo que estava lá a gente explicava na feira, deu certo, era bem simples. A gente até sentiu falta de participação do professor por que muita coisa a gente ficou em dúvida. Não foi uma participação efetiva (Augusto entrevista 2003).

Augusto considerou positiva a experiência como aluno, na qual apresentou de forma demonstrativa um experimento de Física numa Feiras de Ciências. Para ele, foi uma experiência que "deu certo", considerando as motivações e os fins a que o trabalho se propunha, a obtenção de notas e a realização da feira em si: "[...] a gente tinha que estudar pra prova, tinha que dar um trabalho feito pra feira". Entretanto, reconhece que "não foi uma participação efetiva".

No ensino por meio da pesquisa, os trabalhos não são desenvolvidos somente porque há uma exigência institucional da realização de um evento na escola. As Feiras de Ciências constituem-se culminância dos trabalhos escolares desenvolvidos durante um certo período do ano letivo (GONÇALVES e NEVES, 1987). As pesquisas não são realizadas para as feiras, na medida em que esses eventos são resultantes de um processo educativo com ênfase no ensino como investigação (GONÇALVES, 2000). Como podemos perceber na fala de Augusto, acerca do seu trabalho orientado e apresentado na XI FEICIPA:

Pois é, ele [o trabalho] tem uma sequência que eles mesmos fizeram, a gente encaminhava, ia melhorando, melhorando até que ficou o trabalho Biomassa. Em princípio a ideia não era participar de F.C, era de fazer um trabalho, porque quando a gente entrou no clube de ciências a minha ideia era desenvolver um trabalho diferente daqueles que os professores do nível médio desenvolvem [...] a ideia de poder construir junto com eles $o$ conhecimento era algo que eu pensava assim: Se o cara está dizendo que dá, vamos ver na prática (Augusto, entrevista - 2003).

Examinando as falas de Augusto, percebemos que, ao recorrer às suas experiências anteriores como aluno, buscou "estabelecer diferenças entre o que considerava ser um modelo tradicional de ensino", que os professores do nível médio desenvolvem, e a sua prática atual como professor-orientador de projetos de investigação, na qual defende a ideia de poder construir junto com eles [os alunos] o conhecimento. Na perspectiva defendida por Schön (1992), Zeichner (1993), Alarcão (2003), dentre outros, Augusto refletiu sobre a experiência vivenciada, buscando transformar a própria prática, numa ruptura com a visão de docência recebida até então (CARVALHO E GIL-PEREZ, 2001).

Ao se referir ao seu trabalho em Feiras de Ciências como aluno, Augusto se ressente da forma como o seu professor (não) participou do trabalho, assumindo somente o papel de indicar 
um experimento de um livro de Física, solicitando que fosse reproduzido e apresentado na Feira de Ciências. Apesar de envolver a formação de um grupo de estudos, por parte dos alunos, no qual eles interagiam e discutiam entre si, o trabalho consistiu basicamente em uma extensão do modelo tradicional de ensino. Os alunos limitaram-se a reproduzir o discurso presente no livro didático, sem que pudessem apresentar e discutir seus próprios pontos de vista.

Essa concepção tradicional de ensino, como reprodução de ideias, considera o conhecimento como algo pronto, a ser transmitido aos alunos. Nesse processo, as perguntas pré-estabelecidas são de interesse apenas do professor, haja vista que os questionamentos dos alunos não são levados em consideração. No entanto, é essencial que o professor contemple as diferentes formas de pensar dos alunos em seu discurso, sob pena destas formas permanecerem inalteradas (Santos 2000 apud PESSOA, 2005). Como diz a professora Mila:

Como aluna, eu gostava de fazer trabalhos na área de ciências, eu gostava desta parte. Teve uma vez que eu fiz em matemática porque eu precisava de pontos para passar, ai a professora me jogou pra matemática. Foi só na $6^{\circ}$ serie. Nos outros anos foram todos em ciências. Eu sempre gostei desta área de pesquisa e [tinha] interesse por seres vivos, eu gostava de fazer [trabalhos] sobre seres vivos (Mila entrevista 2003).

Um diferencial do ensino como/por pesquisa em relação a uma abordagem tradicional do conhecimento é a valorização da curiosidade dos alunos. A participação deles nas atividades se dá em outros termos, nos quais não está envolvida a atribuição formal de pontos em troca da realização de tarefas escolares, como nos diz a professora Clara:

[os alunos] se sentiram mais interessados em saber mais, pesquisar mais, apesar de que não é aquela coisa do ensino formal que às vezes $o$ professor, por exemplo, consegue um resultado. É assim: olha se você não fizer você não ganha ponto, pro nosso aluno não tem essa história de ganhar ponto, o ganho que ele tem é o conhecimento, que é o mais importante e o nosso objetivo com a associação, com esse modelo de educação é fazer com que os alunos percebam que o conhecimento não pode ser trocado apenas por ponto e sim principalmente pela valorização do meio [ambiente] que ele tem (Clara entrevista - 2003).

O processo de ensino como/por pesquisa tem início com o ato de questionar/duvidar, sendo de fundamental importância que os próprios estudantes estejam envolvidos na problematização de sua realidade (MORAES, GALIAZZI e RAMOS, 2002, PAVÃO, 2006), como dizem os estudantes Bruna e Carlos, ao apresentarem suas questões iniciais de pesquisa:

[...] eu que escolhi porque muita gente fica se perguntado como é que ocorre o processo digestivo e aí me deu a ideia e eu fiz (Bruna entrevista 2003).

A gente escolheu porque... Como é que uma pilha tão pequena pode produzir tanta energia? Ai isto foi uma grande evolução na ciência (Carlos entrevista 2003).

Eu que escolhi... A gente escolheu porque... Bruna e Carlos desenvolveram seus projetos de investigação a partir de questionamentos próprios e por isso fizeram sentido para eles. Ao considerarmos as ideias dos estudantes, devemos pensar num processo educativo voltado para a inquirição (CHASSOT, 2003), de modo a estimular a criatividade dos sujeitos em detrimento da memorização de grandes quantidades de conteúdos (FREIRE, 1999).

A professora Ruth, no entanto, considera que o professor, nos moldes tradicionais, pouco estimula o questionamento e a curiosidade por parte dos alunos, por conseguinte, via de regra, acarreta um distanciamento entre o ensino conteudista desenvolvido nas escolas por estes professores e o ensino por investigação dos Clubes de Ciências.

[...] Às vezes tem uma grande distância entre o que eles veem na escola e no clube de ciências, tanto que no clube eles vão por livre e espontânea vontade, querem aprender, fazer experimentos, eu acho assim, todos eles querem ir por espontânea vontade, curiosidade, o fato de querer "despertar aquela coisa", eles 
são muito curiosos e acho que de certa forma isso na escola não é trabalhado, $o$ conteúdo é aquele e pronto (Ruth entrevista 2003).

Num processo no qual há perguntas e respostas definidas de antemão e o conteúdo é aquele e pronto, não há espaços para críticas, haja vista que os conhecimentos já estão estabelecidos, cabendo ao professor transmitilos. O que ocorre, via de regra, é que, com o avanço da escolarização, a curiosidade característica dos estudantes, vai sendo "abafada" (AMARAL, 2002).

Ruth considera importante a criação de espaços de discussão e diálogo nos quais os estudantes exponham seus pontos de vista, a fim de que possam redimensionar seu entendimento e questionar as ideias discutidas em aula (PESSOA, 2005). Num ambiente de aula com pesquisa, é fundamental que se permita o diálogo crítico (MORAES, 2002, p. 138), como elemento de mediação da aprendizagem, possibilitando aos alunos construção de argumentos próprios, tornando-se mais autônomos.

A avaliação no educar pela pesquisa não visa a analisar apenas o produto, ou seja, o resultado final. Todo o desenvolvimento da pesquisa pode ser avaliado tanto pelo professor quanto pelos colegas de classe, numa avaliação contínua do processo. Portanto, como coloca Moraes (2000, p. 134), "a educação pela pesquisa requer uma forma de avaliação que supere a cópia da cópia".

Desta forma, a educação pela pesquisa supera as limitações da aula tradicional, na medida em que o conhecimento passa a ser (re) construído em aula. Os alunos passam da condição de objetos a sujeitos de sua própria aprendizagem, adquirindo, portanto, mais autonomia, tornando-se "capazes de questionamento, argumentação e produção próprias"(MORAES, 2002,p. 136).

Por outro lado, na medida em que o professor assume a função de "orientador e mediador" no processo de (re) construção de conhecimentos em aula, ele se desenvolve como profissional (MORAES, idem). No ensino como/por pesquisa, professor e alunos compartilham responsabilidades sobre $\mathrm{o}$ andamento das atividades e da produção de significados nas aulas (FREIRE, 1993; CHASSOT, 2003; PESSOA, 2005).

Outro aspecto importante a ser levado em consideração na escolha dos temas questionados pelos estudantes, além da curiosidade deles, é a relevância social da investigação. Como pudemos observar na fala do aluno Lucas:

[...] Foi a partir de uma palestra onde nós estudamos sobre relações ecológicas, eu me interessei em saber mais sobre os danos causados pelos cupins devido aos grandes problemas que estão tendo nas residências do município (Lucas entrevista 2003).

A partir de um conteúdo, o estudo das relações ecológicas entre seres vivos, Lucas se interessou em investigar os danos causados pelos cupins devido aos grandes problemas que estão tendo nas residencias do município. Podemos dizer então que, no ensino por meio da investigação, os conteúdos são considerados como meios para a compreensão de temas socialmente relevantes (AULER e DELIZOICOV, 2001). Essa possibilidade de articulação entre os conceitos científicos e o contexto social (MORTIMER, ROMANELLI e MACHADO, 2000) pode ser evidenciada na fala do professor Augusto:

[...] realmente se você tratar um tópico da física como energia como $\mathrm{E}=\mathrm{mc}^{2}$, ou algo tão técnico nestes termos você vai achar que realmente não tem nada ver com geografia ou a matemática, agora, se você trabalhar da maneira mais geral, da maneira como aparece na vida do cara, vai ser inevitável que esta utilização [dos conceitos científicos] na sua vida tem implicações sociais e inclusive culturais desta maneira; agora, se trabalhado apenas de maneira técnica, não mesmo (Augusto entrevista 2003).

De certa forma, os sujeitos entrevistados buscaram discutir no processo de elaboração de seus trabalhos a importância que a realização de tais investigações teriam para os sujeitos envolvidos. Como apontam os alunos Rita e Lucas:

[...] A gente reuniu o pessoal da escola e levou vários temas os mais variados para a secretaria da escola, nós nos 
interessamos por esse tema da violência porque o nosso bairro é muito perigoso. Fica na periferia, tem muitos grupos de gangues, e como a gente viu que está muito avançada a violência com os jovens, a gente resolveu escolher o tema para ver se conseguimos tirar esse grupo de jovens das ruas (Rita entrevista 2003).

[...] É por causa que lá no lugar que a gente mora, muita gente vive do açaí, então a gente quer conscientizar que não devem destruir o palmito. Porque é uma coisa que está acontecendo [extração exaustiva do açaí], é uma coisa que mexe com a população, quer dizer que as pessoas estão vivendo do açaí e com o tempo esse açaizeiro não vai existir, então estamos levando nosso projeto para que possa haver novos benefícios lá no município (Lucas entrevista-2003).

A questão da relevância social, nessas falas, põe em evidência o seu caráter de pesquisa-ação. Na medida em que o principal objetivo [dos trabalhos de Rita e Lucas] é buscar soluções para um problema dos seus respectivos municípios. A realização das pesquisas tem um caráter eminentemente emancipatório, numa perspectiva de pesquisa-ação voltada para a promoção de igualdade e justiça social (ZEICHNER, 2002).

Destacamos a fala de Lucas, que tem como objetivo conscientizar que não se deve destruir o palmito, porque, senão, com o tempo esse açaizeiro não vai existir. Nesse sentido, Miro busca não apenas divulgar uma problemática do seu município, mas, principalmente, tem a preocupação de possibilitar o "retorno" desta pesquisa, levando nosso projeto para que possa haver novos benefícios lá no município.

As questões discutidas na pesquisa desenvolvida por Lucas estão diretamente relacionadas aos problemas sociais que afetam os cidadãos de sua comunidade. Tal vinculação com uma problemática local possibilita a elaboração de posicionamentos e tomada de decisões, por parte dos sujeitos, quanto ao encaminhamento de suas soluções (Santos e Schnetzler, 2000). Como podemos observar na fala da professora Clara, acerca do seu trabalho:

Acreditamos que a pesquisa-ação possa possibilitar mudanças na realidade por seguir a espiral "planejar-agir-observar-erefletir"'(ZEICHNER E NOFFKE, 2001 apud PEREIRA E ZEICHNER, 2002, p. 75). A pesquisa-ação, ao nosso ver, possibilita ao mesmo tempo a formação dos professores, o desenvolvimento dos alunos e o "retorno" da pesquisa para a comunidade, pois fundamenta-se em "uma tomada de consciência dos atores do problema numa ação coletiva". Outro aspecto evidenciado na fala da professora Clara, ao buscar juntamente com seus alunos mudar essa realidade..., é que por meio da pesquisa, os alunos adquirem capacidade crítica para inquirir as mudanças, tomar decisões e, com isso, promover (trans) formações.

A professora Mariana ressalta a importância de se desenvolver atividades no ensino informal e considera como alguns dos benefícios desta prática pedagógica no que tange ao desenvolvimento de professores e alunos:

(...) a d qu ir $i$ mos no vas
responsabilidades no clube de ciências.
Também foi uma participação ímpar
que hoje enquanto profissional me sinto
impulsionada a levar meus alunos,
porque é nessa hora que a gente começa
a levar nossos alunos a se desenvolver,
ter essa abertura com o público,
pesquisar um projeto e na sala de aula
muitas vezes o aluno fica restrito ao que
o professor fala e às vezes deixamos de
dar oportunidade ao nosso aluno que é
onosso papel, desenvolver habilidades,
fazer pensar e ser um cidadão (Mariana
entrevista, 2003).

A professora Mariana explicita que é papel do professor desenvolver habilidades [do aluno], fazer pensar e ser um cidadão. Daí, a importância de se trabalhar com projetos de pesquisa no desenvolvimento dos alunos, buscando posicionamentos, tomadas de decisão e formação de cidadãos.

No nosso entender, as Feiras de Ciências configuram-se como oportunidades formativas para os professores, à medida que oferecem ocasiões de discussão das práticas pedagógicas dos professores, seja por apresentação propriamente dita de experiências refletidas/estudadas seja pela discussão mais informal nas atividades paralelas e nos momentos de avaliação (GONÇALVES, 2000, p. 54). Como pode ser evidenciado na fala da professora Mara: 
[...] Com certeza é de máxima importância, porque a gente percebe que as pessoas que fazem e participam de feiras, além de poder mostrar os trabalhos é uma oportunidade que temos de ver outros trabalhos e de ter novas ideias para também futuramente quem sabe montar um projeto, por exemplo, o nosso município Acará sediou a primeira vez que veio a FEIRA DE CIÊNCIAS estadual, bacana, estamos tendo a oportunidade de ver outros trabalhos, vamos disseminar para outras pessoas para a nossa área de educação (Mara entrevista - 2003).

Observamos, na fala dos sujeitos de investigação, que um aspecto sine qua non para que seus trabalhos sejam válidos é a divulgação dos resultados da pesquisa. O retorno do conhecimento produzido a partir da pesquisa na escola configura-se em meta a ser alcançada como forma de validação do conhecimento. Considerando a pesquisa como uma atividade pública (STENHOUSE, 1985), assim enfatiza o aluno Flávio:

Nós achamos muito interessante representar aqui o Clube de Ciências e com o objetivo de demonstrar a energia e a preservação, porque temos que preservar os animais nossa fauna, flora e temos que valorizar a ciência do estado. Por que num trabalho de ciências o que acontece, nós adquirimos conhecimento e temos a função de transmitir esse conhecimento para as pessoas e torná-lo ainda mais valido, porque não adianta simplesmente ficar com aquele conhecimento guardado pra você, levar ele para as outras pessoas (Flávio).

Flávio destaca em sua fala a importância da pesquisa desenvolvida, na medida em que culminou com a produção de novos conhecimentos, construção de argumentos acerca do tema (energia do poraquê) investigado, como coloca Moraes (2002, p.72): "em uma sala de aula com pesquisa, o processo de formação através de questionamentos, construção de argumentos e comunicação ocorre tanto no professor como no aluno". Diz Flávio: projetos de maior sucesso. No caso, o projeto do poraquê foi pesquisado há 15 anos atrás. Estamos trazendo ele de volta com novas informações, novas coisas porque acontecem muitas pesquisas fora do Brasil e particularmente aqui no Pará, nós quisemos contar para a população o que o poraquê faz, uma coisa, por exemplo, que eu posso destacar que não está em nenhum livro ou apostila é que quando ele dá uma descarga muito forte, ele faz um barulho que parece um curto circuito, e isso eu não vi em nenhum livro sobre o poraquê(Flávio).

Nesta constante busca pelo conhecimento, num processo interminável de "vir a ser", nós, professores, juntamente com nossos alunos, vamos trilhando nosso caminho em busca de conhecimento e formação, constituindo-nos "sujeitos de nossas aprendizagens", e, consequentemente, críticos, coerentes e autônomos.

\section{CONSIDERAÇÕES FINAIS}

As experiências de professores e alunos participantes da XI FEICIPA e suas histórias na e sobre as Feiras de Ciências foram (com)partilhadas conosco, revelando desenvolvimento e formação profissional, numa perspectiva social da comunicação dos conhecimentos construídos.

Percebemos, a partir do relato dos sujeitos de pesquisa, diferentes oportunidades formativas advindas de suas experiências vividas/compartilhadas em Feiras de Ciências. Os processos/produtos que constituem as Feiras de Ciências apontam para múltiplas relações existentes, demonstram um caráter formativo que se dá em "via de mão dupla". Ao mesmo tempo que os sujeitos se formam, desenvolvendo-se profissionalmente, eles formam também num processo incessante, em busca do conhecimento, de uma completude inalcançável, sem aceitação da realidade como algo pronto e acabado (GONÇALVES, 2000 e FREIRE, 1999).

Acreditamos que um dos caminhos possíveis nesta formação e desenvolvimento profissional do professor passa pela reflexão e investigação da própria prática (SCHÖN, 1992; IMBERNÓN, 2000). E, no caso das Feiras de Ciências, percebemos no momento das entrevistas de nossos sujeitos que ao se 
reportarem às Feiras, ressaltavam experiências vivenciadas como alunos e que foram sobremaneira marcantes, quer tenham sido consideradas positivas, quer não.

Percebemos, a partir do relato dos sujeitos de pesquisa, que o processo de orientação e realização de pesquisa na comunidade constituise diferentes oportunidades formativas para alunos e professores, advindas das experiências por eles vividas e compartilhadas em Feiras de Ciências. São valorizadas pelos sujeitos investigados as oportunidades de socialização e troca de experiências no âmbito da trilogia ensino-aprendizagem-conhecimentos, possibilitando uma ampliação da visão de mundo dos participantes, expositores e visitantes da Feira, permitindo a divulgação dos resultados das pesquisas, troca de experiências entre os pares, como forma de validação dos conhecimentos construídos a partir da realidade investigada

\section{REFERÊNCIAS}

ALARCÃO, I. Professores reflexivos numa escola reflexiva. São Paulo: Ed. Cortez, 2003.

AMARAL, L. O. F. Apresentação do livro: LIMA, M. E. C. de C; AGUIAR, O. G. de; BRAGA, S. A. de M. Aprender ciências: um mundo de materiais. Belo Horizonte: Ed. UFMG, 2004.

AULER. D e DELIZOICOV. D. A L F A B E T I Z A Ç Ã O C I E N T ÍF I C O TECNOLÓGICA PARA QUÊ? . ENSAIO Pesquisa em Educação em Ciências, Volume 03, Número 1 Jun. 2001.

ARAGÃO, R.M.R. Compreendendo a Investigação Narrativa de ações escolares de ensino e de aprendizagem no âmbito da formação de professores. $22^{a}$ Reunião Anual da ANPEd, Caxambu:2004<disponível em: www.anped.org.br/27/gt08/t0818.pdf. acessado em: $15 / 10 / 2005>$.

BAGNO, M. Pesquisa na escola: o que é/ como sefaz? São Paulo: Ed. Loyola, 2003.

CARVALHO, A. M. P; GIL-PÉREZ, D. Formação de Professores de Ciências: tendências e inovações. São Paulo: Ed. Cortez, 2001.
CHAVES,S.N. História e Filosofia da Ciência: Limites e Possibilidades no Ensino de Ciências. Artigo não publicado, 1996.

A construção coletiva de uma prática de formação de professores de ciências : tensões entre o pensar e o agir. Campinas : FE/UNICAMP, 2000. (Tese de Doutorado).

CHASSOT, A. I. Alfabetização Científica: Questões e desafios para a Educação.. 3ed. Ijuí: Ed. Unijuí, 2003.

CONNELLY, F. M. e CLANDININ, D.J. Relatos de Experiência e Oinvestigación Narrativa IN: LARROSA, J. (org) Déjame que te cuente. Ensayos sobre narrativa y educación, Barcelona: EditorIal Laertes, 1995.

CORZO Aula Investigativa: Reencuentro, Análisis de Problemas Universitários $\mathrm{n}^{\circ} 26$.

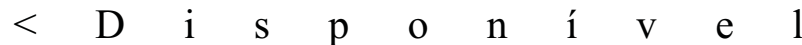
http://reencuentro.xoc.uam.mx/ cuaree/no26/ Aula/Aula.htm, acessado em 16/11/2005>.

FREIRE, P. Pedagogia da Autonomia: saberes necessários à prática educativa. Rio de Janeiro: Paz e Terra, 1999.

GALIAZZI M.C; MORAES, R. Educação pela pesquisa como modo, tempo e espaço de qualificação da formação de Professores de ciências Ciência \& Educação, v. 8, n. 2, p. 237252,2002

GONÇALVES, T. V.O. Ensino de Ciências e Matemática e formação de professores: Marcas da diferenças. Tese (doutorado) Universidade Estadual de Campinas, Faculdade de Educação Campinas, SP, 2000.

Educação Em

Ciências e Comunidade: Investigando a construção de saberes em ensaios de professores na Amazônia Brasileira, Acerca De Uma Prática Docente Diferenciada. Revista da ABRAPEC, 2004.

GONÇALVES, T. V. O; GONÇALVES, T. O. Reflexões sobre uma prática docente situada: Buscando novas perspectivas para a formação de professores. In: GERALDI, C. M. G; FIORENTINI, D; PEREIRA, E. M. de A.(orgs.). Campinas, SP: Editora Mercado de Letras, 1998.

GONÇALVES, T. V. O. e NEVES, S. R. G. 
Feiras de Ciências. São Paulo: Revista do Ensino de Ciências, nº 24, 1987.

HENNING, G.J. Metodologia do Ensino de Ciências. Porto Alegre RS: Ed. Mercado Aberto, 1986.

MANCUSO, R.A. Evolução do Programa de Feiras de Ciências do Rio Grande do Sul. Avaliação Tradicional $X$ Avaliação Participativa. Florianópolis: UFSC, 1993. Dissertação (Mestrado em Educação)Universidade Federal de Santa Catarina, 1993. Contexto Educativo. Revista digital de Educación y Nuevas Tecnologias $\mathrm{N}^{\mathrm{o}}$ 6 , abril 2000.

MORAES, R; GALIAZZI, LIMA, V. M. do R. Pesquisa em sala de aula: fundamentos $e$ pressupostos. Porto Alegre: EDIPUCRS, 2002.

MORTIMER, E.F; e ROMANELLI, L. I. MACHADO, A.H A Proposta Curricular de Química do estado de Minas Gerais: Fundamentos e Pressupostos. In: Química Nova. V. 23, nº 2, p. 273-283, 2000.

OAIGEN, E. $R$, A iniciação à Educação Científica e a compreensão dos fenômenos científicos: a função das atividades informais. Anais do XII ENDIPE, Painel Aberto, Curitiba, 2004.

PAVÃO, A. C. Feiras de Ciências: Revolução Pedagógica. < Disponível e m: www.espacçciencia.pe.gov.br. Acessado em 06/04/06>

PESSOA, W. R. Interações sociais em aulas de química: a conservação de alimentos como tema de estudos. Belém, NPADC/UFPA, 2005 (dissertação de mestrado).

S A N T O S, W. L.P dos. e SCHNETZLER, R.P. Educação em Química: Compromisso com a cidadania. Ijuí: Ed. UNIJUÍ, 2000.

SANTOS, P.R. O Ensino de Ciências e a idéia de Cidadania. Disponível em: http://www.hottopos.com/mirand17/prsantos.h tm. Acessado em: 14/04/2006.

SCHÖN, D. A. La Formación de Profesionales
Reflexivos. Hacia un nuevo diseño de laenseñanza y el aprendizaje en las profesiones. Barcelona: Paidós, 1992.

STENHOUSE, L. La investigación como base de la enseñanza. Madrid, Ediciones MORATA, 1993.

ZEICHNER, K. M. A formação reflexiva de professores: Idéias e Práticas. Lisboa: Educa Professor, 1993. 